\title{
Topography of the Middle Genicular Artery is Associated with the Superior and Inferior Genicular Arteries
}

\author{
La Topografía de la Arteria Genicular Media Está Asociada \\ con las Arterias Geniculares Superiores e Inferiores
}

\author{
Kiwook Yang; Jae-Hee Park; Soo-Jung Jung; Hyunsu Lee; In-Jang Choi \& Jae-Ho Lee
}

YANG, K.; PARK, J. H.; JUNG, S. J.; LEE, H.; CHOI, I. J. \& LEE, J. H. Topography of the middle genicular artery is associated with the superior and inferior genicular arteries. Int. J. Morphol., 35(3):913-918, 2017.

SUMMARY: Total knee arthroplasty has increased substantially, however anatomical studies of the genicular arteries (GAs) in this region are rare. The aim of this study was to identify the pattern and branching points of GAs and their relationship. In 42 lower limbs, the pattern and branching points of GAs were confirmed. The horizontal line which extends between the most prominent point of the lateral and medial margins of patella was defined as a reference line. The distance of branching point of the GAs from the reference line was measured, and the correlations between these points were analyzed. The superior lateral and medial genicular arteries (SLGA and SMGA) were located at $+38.17 \pm 3.10 \mathrm{~mm}$ and $+32.68 \pm 3.83 \mathrm{~mm}$ from the reference line, respectively. The middle genicular artery (MGA) was originated from $+7.57 \pm 3.98 \mathrm{~mm}$. The inferior lateral and medial genicular arteries (ILGA and IMGA) were located at $18.46 \pm 2.63 \mathrm{~mm}$ and $-24.09 \pm 3.52 \mathrm{~mm}$, respectively. The branching points of the SLGA changed significantly according to the arterial branching pattern with the MGA. In addition, the branching point of the MGA had positive relationships with that of the IMGA ( $\mathrm{r}=$ $0.385, \mathrm{p}<0.05)$ and that of the ILGA $(r=0.348, \mathrm{p}<0.05)$, respectively. In this study, topography of the GAs and its anatomical association were demonstrated for the first time in Korean cadavers. Knowledge of the topography about frequent variation would be useful for safe surgery and clinical procedures.

KEY WORDS: Genicular artery; Popliteal artery; Topography; Variations.

\section{INTRODUCTION}

The arterial supply of the knee has been classically described as a vascular network, so called the genicular artery. The genicular arteries are the branches of the femoral and popliteal arteries (PA) which have six kinds of branches, the descending genicular artery, the superior medial genicular artery (SMGA), the superior lateral genicular artery (SLGA), the middle genicular artery (MGA), the inferior medial genicular artery (IMGA) and the inferior lateral genicular artery (ILGA). Except the descending genicular artery which is the femoral arterial branch, five genicular arteries are the branches of the PA in popliteal fossa. These genicular arteries (GAs) form a vascular network by the anastomosis of collateral branches from the main artery in popliteal fossa (Quain \& Maclise, 1844).

Previous studies demonstrated that the variation of the PA is frequent and its patterns have been established for a long times by many authors (Adachi \& Hasebe, 1928; Lippert
\& Pabst, 1985). With the advent of diagnostic techniques like angiographic approach, recent studies support the knowledge about the branching pattern of the PA (Kim et al., 1989; Day \& Orme, 2006). However, anatomical analysis about the GAs as the branches of the PA was rare because their clinical significance was relatively lack. Few studies focused on anatomical variations of the GAs (Salaria \& Atkinson, 2008; Shahid et al., 2015), and this studies were scarce in Korean population. As the vascular complications in total knee arthroplasty occurs continually (Katsimihas et al., 2001; Memtsoudis et al., 2008), precise studies on the arrangement of this vascular network may be extremely valuable.

In this article, topographic anatomy of the GAs was analyzed to find out the branching pattern of the GA and their correlation. This knowledge contributes to extend clinical implication for invasive procedures and embryological basis of these arteries. 


\section{MATERIAL AND METHOD}

Identification of the genicular arteries: In this study, 42 lower limbs (in 22 cadavers, 22 right and 20 left) were dissected. Each cadaver was placed prone position. The skin, superficial fascia, and adipose tissue were removed to expose the flexor compartment of the popliteal fossa. The popliteal artery and its branches were dissected from the nerve and the fascia. After the SMGA, SLGA, MGA, IMGA, and ILGA were dissected, branching patterns of these arteries was confirmed. The horizontal line extended from the most prominence apex of the lateral margin of patella was defined as the reference line. The diameter of each artery was measured by using digital calipers (NA500-300S, Blue bird, Korea).

Topographic anatomy of the genicular arteries and their correlation. All GAs were originated from the PA. The branching point and pattern of the GAs were analyzed. The branching point was defined as the length from the reference line to the branching point of each artery. All of above points were calculated as a millimeter by reference line. From the reference line, upper and lower points were recorded as $(+)$ and (-), respectively. The correlation between the branching points of the GAs was analyzed, and their difference was compared according to the branching pattern of the GAs.

Statistics. The SPSS statistical package (SPSS software, version 20.0; SPSS, Inc., Chicago, IL) was used for all statistical analyses. The difference of branching point according the pattern was analyzed by Mann-Whitney U test. Correlation between these variables was analyzed by Spearman correlation analysis. $\mathrm{P}$ values $<0.05$ were considered to indicate statistically significant results.

\section{RESULTS}

The branching patterns of the genicular artery. We clearly confirmed the GAs in all 42 cases (Fig. 1). Most of cases have separate branches of the GAs normally (76.19 $\%, 32$ limbs of total $42 \mathrm{limbs}$ ). The variation in these arteries was $23.81 \%$ (10/42 limbs). It was found bilaterally in one cadav-er and unilaterally in 8 cadavers (6 of the right side and 4 of the left side). The branching pattern of the GAs had five types (Fig. 2). First, all kinds of the GAs were branched separately in thirty two limbs. Second, the SMGA and the MGA had a common trunk in four limbs. Third, the ILGA and the IMGA were branched together in three limbs. Fourth, the MGA and the IMGA shared common trunk in two limbs. And last, the MGA, the SMGA and the SLGA were branched together in one limb.

The diameter of the genicular artery. The averages of the diameter of the SMGA and SLGA were $1.68 \pm 0.93 \mathrm{~mm}$, $1.39 \pm 0.63 \mathrm{~mm}$, respectively (Fig. 3). The diameter of the MGA $(1.31 \pm 0.39 \mathrm{~mm})$ was significantly smaller than SMGA $(p=0.024)$. The averages of the diameter of the

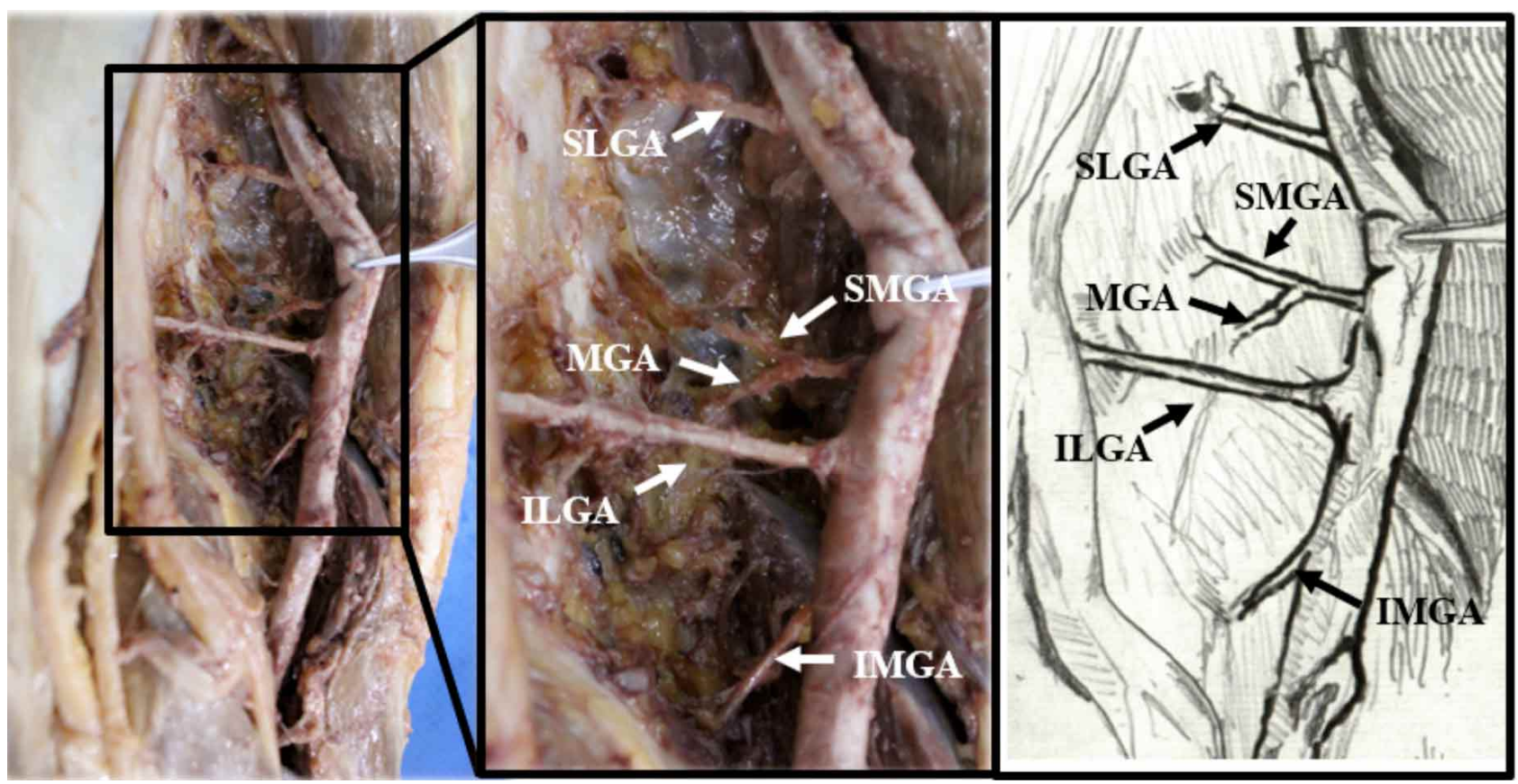

Fig. 1. Representative image of the branches of the genicular artery. ILGA, inferior lateral genicular artery; IMGA, inferior medial genicular artery; MGA, middle genicular artery; SLGA, superior lateral genicular artery; SMGA, superior medial genicular artery. 

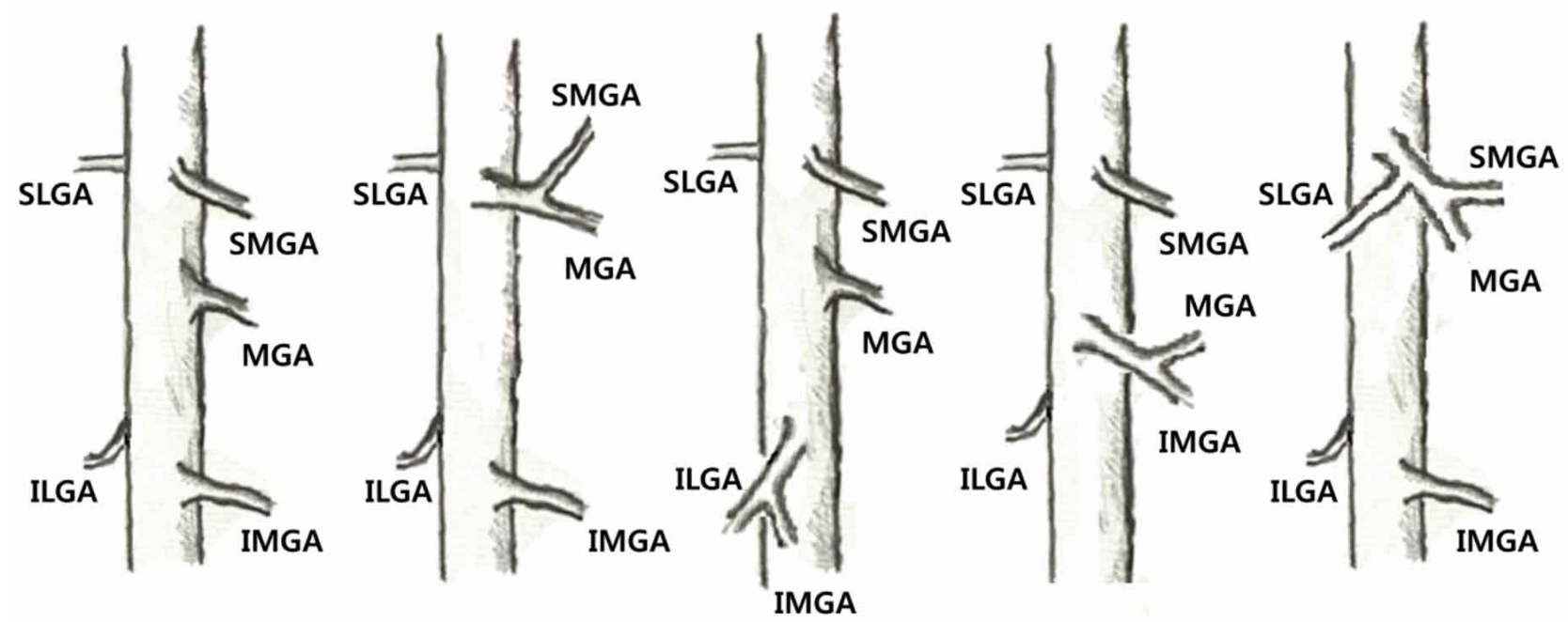

Fig. 2. Types of branching pattern of the genicular artery.

IMGA and ILGA were $1.40 \pm 0.46 \mathrm{~mm}, 1.37 \pm 0.45 \mathrm{~mm}$, respectively. There was no significant difference between the diameters in these arteries except between the SMGA and the MGA.

Topography of the genicular artery. The topographic anatomy of the GAs from the reference line is shown in Fig. 4. The SLGA and SMGA were located $+38.17 \pm 3.10 \mathrm{~mm}$ and $+32.68 \pm 3.83$ from the reference line, respectively. The MGA was located $+7.57 \pm 3.98 \mathrm{~mm}$ from the reference line. The ILGA and IMGA were originated from $-18.46 \pm 2.63$ $\mathrm{mm}$ and $-24.09 \pm 3.52$ on the reference line, respectively. The branching points of the SLGA were changed according to the arterial branching pattern with the MGA. The SLGA was originated from lower level $(23.77 \pm 6.61 \mathrm{~mm})$ in cases with common trunk for the MGA than in cases with separated

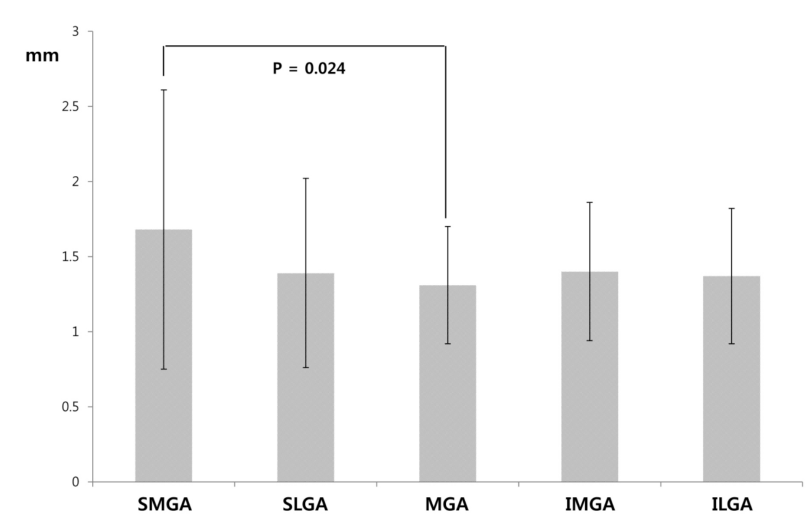

Fig. 3. The diameters of the genicular artery. The diameter of the superior medial genicular artery was significantly wider than that of the middle genicular artery.
SLGA (42.82 $\pm 3.13 \mathrm{~mm}, \mathrm{p}=0.007)$. The branching points of the SMGA were also different $(20.27 \pm 8.85$ vs $36.69 \pm$ 4.02), however, it did not get a statistical significance ( $\mathrm{p}=$ $0.065)$.

Correlation between the branching points of the genicular arteries. The quantitative correlation between the branching points of the GAs was analyzed and presented in Table I. There was a significant positive relationship between

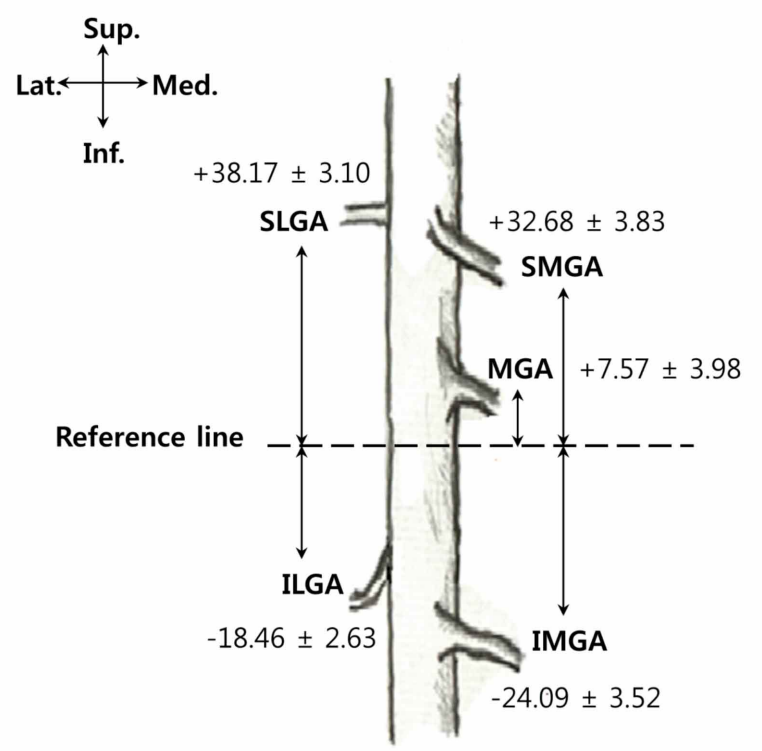

Fig. 4. Topographic anatomy of the genicular artery. ILGA, inferior lateral genicular artery; IMGA, inferior medial genicular artery; MGA, middle genicular artery; SLGA, superior lateral genicular artery; SMGA, superior medial genicular artery. 
the SLGA and the SMGA (Pearson correlation test, $r=0.663, p<0.05$, Fig. 5a). The ILGA and the IMGA also showed a strong correlation (Pearson correlation test, $r=0.799, p<0.05$, Fig. $5 b)$. And the MGA had positive relationship with the ILGA $(r=0.348$, $\mathrm{p}<0.05$, Fig. $5 \mathrm{c})$ and the IMGA $(\mathrm{r}=$ $0.385, \mathrm{p}<0.05$, Fig. 5d), respectively. However, there was no correlation between other GAs.
Table I. The quantitative correlation between the branching points of the genicular arteries.

\begin{tabular}{llcllll}
\hline & & SMGA & SLGA & MGA & IMGA & ILGA \\
\hline SMGA & Correlation coefficient & 1 & $\mathbf{. 6 6 3}$ & .208 & -.069 & .122 \\
& P value & & $\mathbf{. 0 0 0}$ & .204 & .676 & .454 \\
SLGA & Correlation coefficient & & 1 & -.009 & -.157 & .097 \\
& P value & & & .957 & .339 & .556 \\
MGA & Correlation coefficient & & & 1 & $\mathbf{. 3 8 5}$ & $\mathbf{. 3 4 8}$ \\
& P value & & & & $\mathbf{. 0 1 7}$ & $\mathbf{. 0 3 2}$ \\
IMGA & Correlation coefficient & & & & 1 & $\mathbf{. 7 9 9}$ \\
& P value & & & & $\mathbf{. 0 0 1}$ \\
\hline
\end{tabular}

ILGA, inferior lateral genicular artery; IMGA, inferior medial genicular artery; MGA, middle genicular artery; SLGA, superior lateral genicular artery; SMGA, superior medial genicular artery.

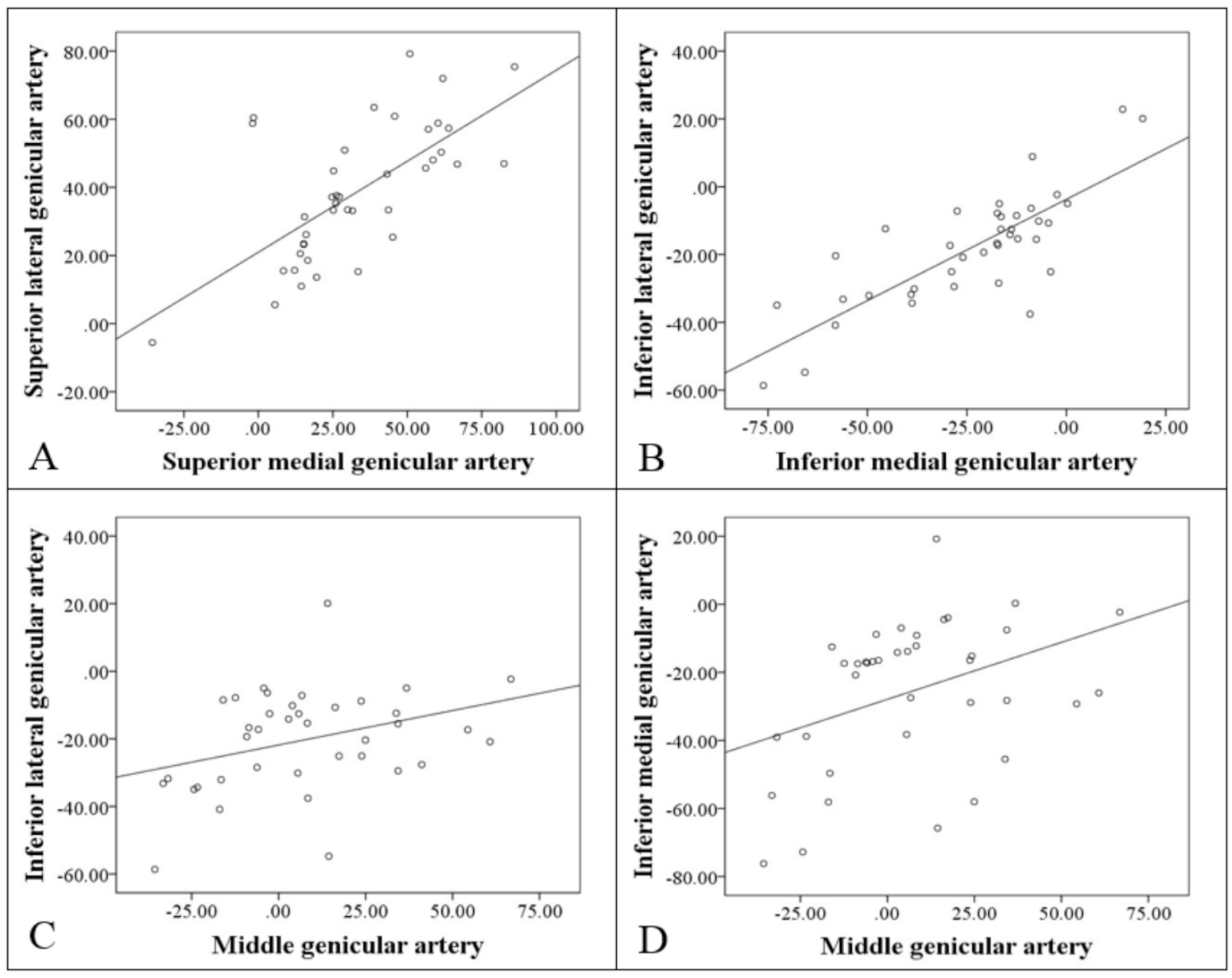

Fig. 5. Relationship between the genicular arteries. (A) Relationship between the superior lateral genicular artery and the superior medial genicular artery (Pearson correlation test, $\mathrm{r}=0.663, \mathrm{p}<0.001$ ); (B) the inferior lateral genicular artery and the inferior medial genicular artery $(\mathrm{r}=0.799, \mathrm{p}<0.001)$; $(\mathrm{C})$ the inferior lateral genicular artery and the middle genicular artery $(r=0.385, \mathrm{p}<0.05)$; (D) the inferior medial genicular artery and the middle genicular artery $(\mathrm{r}=0.348, \mathrm{p}<0.05)$. 


\section{DISCUSSION}

In this study, the branching patterns of the genicular artery and its relationship in Korean cadaver were invested. In earlier study, the four types of the branching patterns of the genicular artery were found but its relationship was not studied (Shahid et al.). Moreover, they pointed out that the presence of the complication of the knee surgery might be related with the variations of the genicular artery (Katsimihas et al.; Smith et al., 2001; Soldado et al., 2002; Memtsoudis et al.). However, there were no previous articles about anatomical data for reducing the complications. To my best knowledge, the present study is the first article which demonstrates branching patterns of the genicular arteries and their relationship.

The incidence of the variation of the GA was found in $23.81 \%$. Comparable with the findings of the earlier study (Shahid et al.), the five kinds of the branching patterns of the genicular artery was found in 42 limbs. Most frequent variation was the combination of the MGA and the SMGA. The MGA and the IMGA were frequently combined together. These data suggested that the MGA tends to be not a separate branch in some cases, but a branch of the GAs in medial side. Interestingly, the origin of the SLGA was significantly different according to the branching pattern of the MGA. When the MGA was combined with the other GAs medially located (SMGA or IMGA), the SLGA was originated from lower level. However, their diameter was not different according to the patterns of GAs though the diameters were in agreement with previous study (Shahid et al.). It indicated that the branching pattern of the MGA may be associated with the position of the SLGA. It was hypothesized that when the MGA frequently combined with the other GAs, blood supply of some part of the MGA will be scarce. In order to supply this part, the location of the SLGA need be changed inferiorly considering that hemodynamics induced the formation of vessels (Dunlap et al., 1989).

To clarify the topographic relationship in these arteries, quantitative correlations of their branching points were analyzed. Expectedly, there was strongly positive association between the SMGA and SLGA, and between the IMGA and ILGA. Interestingly, the MGA had positive relationship with the IMGA and ILGA. Based on simultaneous development of vessels during embryogenesis, it was suggested that angiogenesis of the MGA may be associated with that of the inferior GAs. Its embryological mechanism and effect should be confirmed with larger cases.

In this study, we demonstrated topography of the GAs and its anatomical association for the first time. Though it was still a hypothesis, strong relation between the GAs may lead new trend for anatomical study. This data encourages further development of this concept of variation study. Knowledge of topography about frequent variation would be useful for safe surgeries and clinical procedures without iatrogenic complications.

\section{ACKNOWLEDGEMENTS}

This research was supported by the Keimyung University Research Grant of 2015.

YANG, K.; PARK, J. H.; JUNG, S. J.; LEE, H.; CHOI, I. J. \& LEE, J. H. La topografía de la arteria genicular media está asociada con las arterias geniculares superiores e inferiores. Int. J. Morphol., 35(3):913-918, 2017.

RESUMEN: La artroplastía total de rodilla ha aumentado sustancialmente, sin embargo los estudios anatómicos de las arterias geniculares (AGs) en esta región son escasos. El objetivo de este estudio fue identificar los patrones y puntos de ramificación de las AGs y sus relaciones. En 42 miembros inferiores, se identificaron el patrón y los puntos de ramificación de las AGs. La línea horizontal que se extiende entre el punto más prominente de los márgenes lateral y medial de la patela se definió como una línea de referencia. Se midió la distancia entre el punto de ramificación de las AGs y la línea de referencia, y se analizaron las correlaciones entre estos puntos. Las arterias geniculares superiores lateral y medial (AGSL y AGSM, respectivamente) se situaron a $+38,17 \pm$ $3,10 \mathrm{~mm}$ y $+32,68 \pm 3,83 \mathrm{~mm}$ de la línea de referencia, respectivamente, y la arteria genicular media (AGM) se originó a partir de + 7,57 $\pm 3,98 \mathrm{~mm}$. Las arterias geniculares inferiores lateral y medial (AGIL e AGIM, respectivamente) se localizaron a - 18,46 $\pm 2,63$ $\mathrm{mm}$ y - 24,09 $\pm 3,52 \mathrm{~mm}$, respectivamente. Los puntos de ramificación de la AGSL cambiaron significativamente de acuerdo con el patrón de ramificación arterial con respecto a la AGSM. Además, el punto de ramificación de la AGSM tuvo relaciones positivas con el de la AGIM ( $r=0.385, \mathrm{p}<0.05)$ y el de la AGIL ( $\mathrm{r}=$ $0.348, \mathrm{p}<0.05$ ). En este estudio, la topografía de las AGs y su asociación anatómica se demostraron por primera vez en cadáveres coreanos. El conocimiento de la topografía sobre la variación frecuente sería útil para su aplicación en el desarrollo de cirugías y procedimientos clínicos seguros.

PALABRAS CLAVE: Arteria genicular; Arteria poplítea; Topografía; Variaciones.

\section{REFERENCES}

Adachi, B. \& Hasebe, K. Das Arteriensystem der Japaner. Kyoto, Kaiserlich-japanische Universität zu Kyoto, in kommission bei" Maruzen Co.", 1928. 
YANG, K.; PARK, J. H.; JUNG, S. J.; LEE, H.; CHOI, I. J. \& LEE, J. H. Topography of the middle genicular artery is associated with the superior and inferior genicular arteries. Int. J. Morphol., 35(3):913-918, 2017.

Day, C. \& Orme, R. Popliteal artery branching patterns-an angiographic study. Clin. Radiol., 61(8):696-9, 2006.

Dunlap, J.; McCarthy, J. A.; Joyce, M. E.; Ogata, K. \& Shively, R. A. Quantification of the perfusion of the anterior cruciate ligament and the effects of stress and injury to supporting structures. Am. J. Sports Med., 17(6):808-10, 1989.

Katsimihas, M.; Robinson, D.; Thornton, M. \& Langkamer, V. G. Therapeutic embolization of the genicular arteries for recurrent hemarthrosis after total knee arthroplasty. J. Arthroplasty, 16(7):935-7, 2001.

Kim, D.; Orron, D. E. \& Skillman, J. J. Surgical significance of popliteal arterial variants. A unified angiographic classification. Ann. Surg., 210(6):776-81, 1989.

Lippert, H. \& Pabst, R. Arterial Variations in Man: Classification and Frequency. München, J. F. Bergmann Verlag, 1985.

Memtsoudis, S. G.; González Della Valle, A.; Besculides, M. C.; Gaber, L. \& Sculco, T. P. In-hospital complications and mortality of unilateral, bilateral, and revision TKA: based on an estimate of 4,159,661 discharges. Clin. Orthop. Relat. Res., 466(11):2617-27, 2008.

Quain, R. \& Maclise, J. The Anatomy of the Arteries of the Human Body: And Its Applications to Pathology and Operative Surgery with a Series of Lithographic Drawings. London, Taylor and Walton, 1844.

Salaria, H. \& Atkinson, R. Anatomic study of the middle genicular artery. J. Orthop. Surg. (Hong Kong), 16(1):47-9, 2008.

Shahid, S.; Saghir, N.; Cawley, O. \& Saujani, S. A cadaveric study of the branching pattern and diameter of the genicular arteries: A focus on the middle genicular artery. J. Knee Surg., 28(5):417-24, 2015.

Smith, D. E.; McGraw, R. W.; Taylor, D. C. \& Masri, B. A. Arterial complications and total knee arthroplasty. J. Am. Acad. Orthop. Surg., 9(4):253-7, 2001

Soldado, F.; Reina, F.; Yuguero, M. \& Rodríguez-Baeza, A. Clinical anatomy of the arterial supply of the human patellar ligament. Surg. Radiol. Anat., 24(3-4):177-82, 2002

\section{Corresponding author: \\ Jae-Ho Lee \\ Department of Anatomy \\ Keimyung University \\ School of Medicine, 2800 \\ Dalgubeoldaero \\ Dalseo-Gu \\ Daegu \\ REPUBLIC OF KOREA}

E-Mail: purme2000@naver.com

Received: 21-03-2017

Accepted: 19-05-2017 